\title{
Linking an Integrative Behavior Model to Elements of Environmental Campaigns: An Analysis of Face-to-Face Communication and Posters against Littering
}

\section{Ralph Hansmann ${ }^{1, *}$ and Nora Steimer ${ }^{2}$}

1 Department of Environmental Systems Science (D-USYS), Natural and Social Science Interface (NSSI), ETH Zurich, Sonneggstrasse 33, ETH SOL F.7, CH-8092 Zurich, Switzerland

2 IG Saubere Umwelt (IGSU), Naglerwiesenstrasse 4, CH-8049 Zurich, Switzerland; E-Mail: nora.steimer@igsu.ch

* Author to whom correspondence should be addressed; E-Mail: ralph.hansmann@env.ethz.ch; Tel.: +41-44-632-63-16.

Academic Editor: Armin Lude

Received: 6 March 2015 / Accepted: 21 May 2015 / Published: 29 May 2015

\begin{abstract}
Diverse elements of anti-littering campaigns may be effective at addressing different causes of littering. Therefore, a complementary approach combining various elements is needed to ensure the behavioral effectiveness of corresponding campaigns. The present study investigates personal, problem-centered face-to-face conversations compared to three different types of anti-littering posters (witty, authoritarian, environmentally oriented). In total, $N=147$ persons participated in the questionnaire-based survey. Pictures of the three anti-littering posters were presented to all respondents, but only 82 of them additionally took part in problem-centered face-to-face conversations. Participants of the latter condition liked the conversations significantly more and judged them more effective for reducing littering than each of the three posters. Intentions for future behavior also improved more in the condition with face-to-face communications than in the reference condition in which only the anti-littering posters were presented. Regarding the posters, it was found that the witty and the environmentally-oriented poster were liked more and judged to be more effective by the respondents than the authoritarian poster. Findings are discussed in relation to the design of campaigns, which combine elements with reference to an integrative behavior model covering a broad range of factors, including processes of justifications, habit formation and reactance.
\end{abstract}


Keywords: environmental education; sustainability; littering; communication; face-to-face; slogans; reactance; justifications; habits

\section{Introduction}

\subsection{The Interactive Approach of Anti-Littering Ambassadors}

The pollution of the environment through littering is a serious problem that causes high cleaning costs and negatively affects the aesthetic value of nature and urban settlements. Ultimately, it can have a negative impact on the quality of life and reduce the residential satisfaction of citizens. In Switzerland, the Interest Group for a Clean Environment (IGSU, Interessengemeinschaft saubere Umwelt) is engaged in various activities to counteract the littering problem, such as organizing clean-up days, providing educational materials and designing anti-littering posters. Since 2007, IGSU has also engaged so-called anti-littering ambassadors who personally approach people in public spaces and involve them in face-to-face communication on the topic of littering in order to increase their awareness of the littering problem and strengthen the development of personal anti-littering norms (Figure 1). Each year, the ambassador teams visit public places, in particular "littering hotspots", as well as schools in around 40 Swiss cities and municipalities. Thus, in 2014, about 80 IGSU ambassadors were active in different regions of Switzerland to talk directly with people about the littering problem. In total, their activities make up approximately $16,000 \mathrm{~h}$ of environmental communication and raising awareness annually.

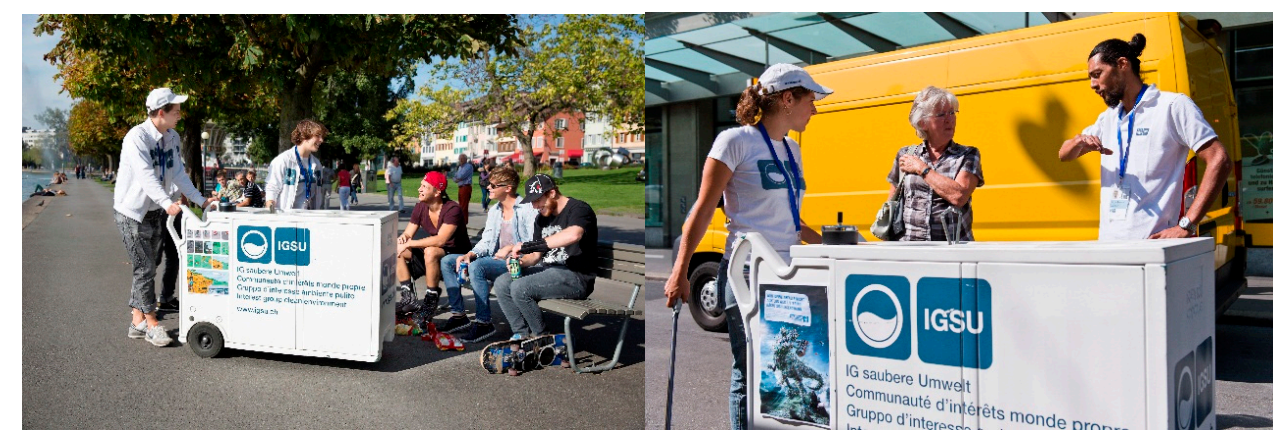

Figure 1. Photos of anti-littering ambassadors performing their face-to-face communication activity.

The personal approach of ambassador teams involves close social interaction and is clearly distinct from unilateral media campaigns. The anti-littering ambassadors and the target persons get involved together socially and content-wise in a discussion centered on the topical field of littering and associated problems. They discuss the topic with each other and search for solutions of the littering problem cooperatively.

Various studies indicate that interactive, personal face-to face communication tends to be more effective in changing attitudes and behaviors as compared to one-directional communication through media [1]. Face-to-face communication has been shown to be particularly helpful, when the aim is to cooperatively solve an environmental and social dilemma [2-4]. It is important for this that the communication is authentic to establish mutual trust between the discussants, so that positive 
behavioral norms can be established or strengthened $[5,6]$. The exchange of opinions on equal footing is crucial, since authoritarian one-sided communication in a commanding tone can trigger psychological reactance, which can prevent the acceptance and internalization of positive behavioral norms $[7,8]$. The ambassadors are instructed to conduct their talks in a flexible way and to encourage their counterparts to express their own opinions, experiences and interests. This way, they can address justifications, which their counterparts eventually provide for their own littering behaviors committed in the past. According to the neutralization theory $[9,10]$, which has recently been transferred from the domain of delinquency to environmentally-harmful behaviors [11-13], justifications facilitate deviant behaviors, because they can neutralize positive personal behavioral norms. Therefore, justifications can help to explain the discrepancy between attitudes and behavior, which has received much attention in environmental behavior research and has so far only been resolved partially by concepts, such as perceived behavioral control, values, beliefs and social norms [14-18].

Environmental education, communication and campaigns aim to convey socially-approved norms to promote positive environmental behaviors, as for example to dispose of waste properly. Figure 2 shows at which points of the behavior change process reactance and justifications can deteriorate the behavioral effectiveness of environmental communication and campaigns. While reactance prevents the internalization of social norms, justifications can block the behavioral effectiveness of these norms even if they have been internalized. Furthermore, justifications formed after a norm-deviating behavior (i.e., rationalizations according to the neutralization theory of Sykes and Matza [10]) can serve as neutralizations for norm violations in the future and can hence stabilize negative behavior over time leading to habits of misconduct (Figure 2). Negative habits represent a great challenge for environmental communication. According to Lewin [19], changing habits requires an unfreezing of existing habits, shifting behavior to a new desired form and then refreezing the new behavior. Dahlstrand and Biel [20] argue that raising awareness for a need for change is necessary before new positive behaviors can be identified and corresponding habits of environmental behavior can be established.

Face-to-face communication allows for inquiring and challenging habits and underlying belief systems of the target persons flexibly. Arguments can be introduced in a variable way contingent on statements of the counterparts to promote desired insights, attitudes and opinion changes [21]. Eventually, positive arguments and opinions are then also formulated and expressed by the target persons themselves, so that they commit themselves openly to non-littering behavior. The latter is helpful, as previous research shows that statements of self-commitment promote the actual performance of specific behaviors [22].

Face-to-face communication of anti-littering ambassadors can also be directed to small groups of persons who are present in public places (Figure 1). In this case, the ambassador partially takes on the role of the moderator of a small group discussion. The group interaction process, which he or she guides, may alter group norms and future group dynamics in a desired direction. 


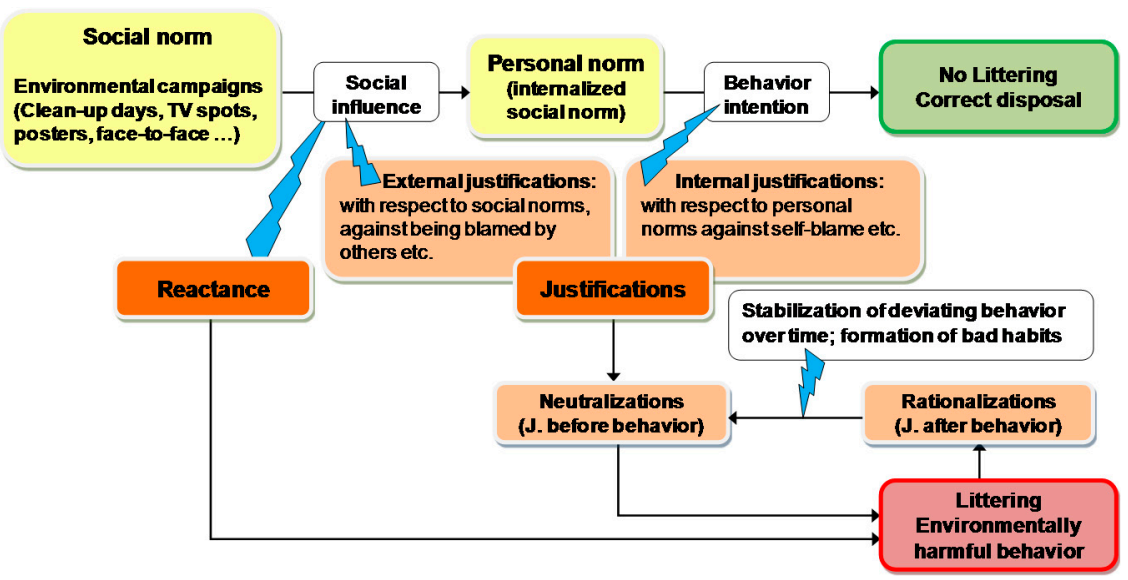

Figure 2. Environmental campaigns aim to convey social norms for positive environmental behaviors to target persons. Psychological reactance can prevent the internalization ofthese social norms, and justifications can limit their behavioral effectiveness, even after successful internalization. Furthermore, justifications for norm-deviating behaviors in the past (rationalizations) can serve as justifications (neutralizations) for similar negative behaviors in the future and may thus stabilize misconduct over time (with reference to Sykes and Matza [10]).

A strong influence of face-to-face communication as compared to communication through media is also suggested by psychological models of persuasion, which hold that the strength of social influence decreases with the psychological distance between the source and the target of the influence and with the number of persons that are targeted $[23,24]$.

\subsection{Linking an Integrative Behavior Model to Sustainability-Oriented Campaigns}

Campaigns aiming to promote positive environmental behavior are often not confined to one activity and medium. Instead, they frequently combine several campaign elements with the same objective together under one roof. In addition to one-way communication by posters, flyers and TV spots, interactive elements, such as clean-up days, public events with panel discussions, cultural performances, competitions and the organization of waste-free zones have been used to achieve the active involvement of target groups [25]. From a psychological perspective, a complementary diversity of campaign elements is useful, since different campaign elements can tackle different causes of littering. This is crucial, since a variety of causes may be underlying this problematic behavior. Determinants of environmental behavior include personal factors, as well as social and further situational influences [26]. Personal factors are, for example, the knowledge and competencies of a person, his or her environmental awareness, personal values, norms and attitudes, as well as goals, beliefs, expectations and habits. Social influences are exerted by formal and informal societal, organizational and group norms, by the social role of a person and by group dynamics. In addition, the actual and perceived options and constraints of a given situation determine the behavior of a person.

Therefore, a complementary approach combining various elements is needed to ensure behavioral effectiveness. For example, clean-up events in schools or in a sports club involve children and youth together with their peers (e.g., the school class or sports team), and the joint personal experiences and 
social interaction may promote positive personal norms, as well as collective group norms against littering. In depth, systemic knowledge of the negative consequences of littering may be best conveyed through waste education in school or through brochures and TV reports, whereas posters or short TV spots may be effective at raising awareness and motivating people to stop littering by conveying brief salient information through creative slogans. Because of the close social interaction and flexibility, face-to-face communication may be well suited to counteract justifications and raise awareness for the need to change bad habits if existent. An integrative behavior model, which considers the manifold determinants of behavior, seems important for the design of effective campaigns that use complementary elements to achieve a common goal. A draft for such an integrative behavior model is provided in Figure 3. The model was formed in an eclectic approach to include behavioral determinants and processes conceptualized in various models, such as the theory of planned behavior [14], the norm-activation model [27], value-belief-norm theory [18], neutralization theory [10] and Lewin's change theory [19], and further accounts for habit formation and change [20]. It is clear that this model only represents a conceptual draft and is, in principle, open to the inclusion of additional predictors and processes. However, the model includes multiple causes of environmental behavior and also entails processes of reactance, justification and the formation of habits. According to the model, habitual behavior takes place almost automatically without elaborated justification processes weighing the pros and cons. Instead, behavior, which often proves successful in the past, is repeatedly displayed without much conscious internal deliberation. Littering may prove successful in so far as the litterer thereby gets rid of unwanted waste and thus achieves the primary objective of disposal behavior. If no one makes litterers accountable and criticizes their misbehavior, littering can thus become a bad habit. To change such littering habits, interventions are necessary to raise awareness with respect to the dysfunctional character and negative consequences of littering. Brief slogans on posters may be well suited to raise such awareness. However, in addition to this, personal face-to-face communication can elicit, tackle, discuss and criticize individual justifications for littering specifically and in-depth.

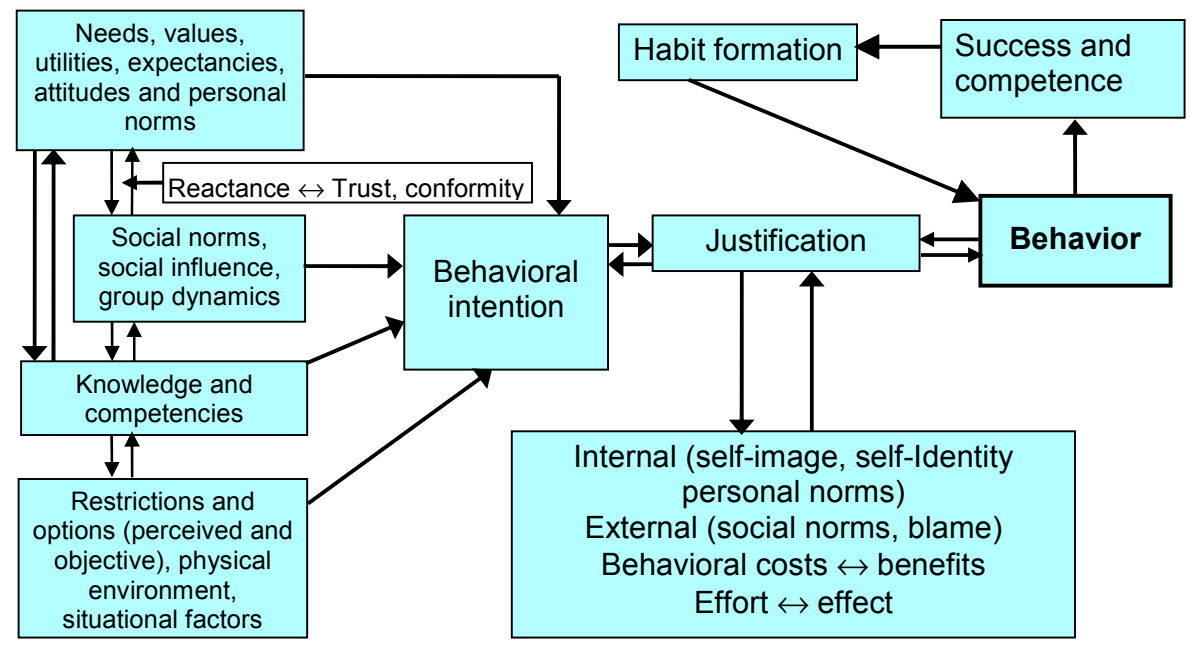

Figure 3. Integrative behavior model covering diverse personal and environmental determinants and processes of social influence, reactance, justification and habit formation. 


\subsection{Aim of the Study and Hypotheses}

In line with the previous reasoning, the main goal of this research is to investigate how posters and face-to-face communication can complement each other in counteracting littering. In relation to posters, a further research aim is to find out which types of slogans should be used to maximize their effectiveness.

Various studies on the use of anti-littering prompts have shown that friendly slogans, which for example, ask for help in maintaining the cleanliness of the environment, are more effective than slogans in a commanding authoritative tone [28-32]. Authoritarian and rude speech can seriously reduce the acceptance of a poster and even trigger adverse reactions [33]. These findings can be explained by reactance theory [7,8], as well as by self-determination theory [34,35], which both state that people strive for autonomy and self-determination and, accordingly, wish to determine their values and norms freely [36]. External coercion and pressure to behave in a certain way can thus elicit reactant motivation, which can prevent the adoption of the communicated norms. An open question in this regard is how far humorous communication can circumvent reactance and effectively motivate people for positive behavior changes. This question is highly relevant, as many anti-littering campaigns actually use humorous communication. The present study will therefore investigate and compare posters with prototypes of an authoritative, a humorous and a straightforward environmentally-oriented slogan.

In line with reactance theory $[7,8]$ and findings from a previous study on the perception of slogans promoting recycling [31], it was expected that the participants would like posters with a humorous or environmentally-oriented slogan more than an authoritative poster (Hypothesis 1). One part of this hypothesis is also supported by studies on advertising, which found that witty slogans are liked very much by the public [37].

In line within with the mentioned study on slogans promoting recycling [31], it was expected that the participants would judge posters with a humorous or environmentally-oriented slogan to be more effective than an authoritative poster against littering (Hypothesis 2).

Face-to-face communication of anti-littering ambassadors involves close social interaction and the active participation of the target groups. Psychological considerations outlined in the two previous sections suggest that the approach is behaviorally very effective. Therefore, two further hypotheses were formulated with respect to the face-to-face communication.

Firstly, it was expected that effectiveness ratings for the personal face-to-face conversations would be higher than for the investigated posters (Hypothesis 3).

Secondly, it was expected that the stated intentions for future behavior would indicate more positive psychological changes among respondents taking part in the face-to-face conversation (in addition to the presentation of the three posters) as compared to respondents who were solely presented with the three posters (Hypothesis 4).

\section{Method}

\subsection{Experimental Design and Procedure}

A quasi-experimental field study with two conditions was conducted. A condition where three posters were presented to the respondents served as a control condition for the experimental condition with face-to-face communication and presentation of these posters. The main focus is accordingly the 
investigation of the effects that face-to-face communication can achieve complementarily to the presentation of posters. A questionnaire (see Section 2.2) was used to measure the perception of the posters and the face-to-face communication and their psychological effects. For practical reasons, no measures based on the observation of actual behavior or behavioral traces could be taken. It also felt inappropriate to observe people after a face-to-face communication involving the building of mutual trust.

The participants of the two conditions were recruited in the same public places, but on different days. On some days, face-to-face conversations were conducted, and the anti-littering ambassadors handed out the questionnaire immediately after these talks, whereas on the other days, passers-by at the same locations were briefly asked to participate in a survey on disposal behavior. Accordingly, there was no random assignment of the persons to the conditions.

Five anti-littering ambassadors with considerable experience individually conducted the face-to-face communications with single persons. The same persons who conducted the face-to-face communications also recruited the participants of the control condition. They were instructed to contact similar persons when recruiting participants for both conditions, but exact quota for gender and age were not provided. The questionnaires were distributed during two weeks from Tuesday to Saturday between 11 a.m. and 17 p.m. The recruiters, respectively anti-littering ambassadors, wore white shirts or jackets with the IGSU logo when recruiting participants (compare Figure 1).

An average face-to-face communication took about five minutes, whereas in the control condition, only a few seconds were needed to ask passers-by for participation in the questionnaire survey. In both conditions, a first self-selection took place, as not all contacted persons agreed to voluntarily take part in a face-to-face communication, respectively to take a questionnaire with them. Still, a clear majority agreed to participate, respectively take a questionnaire. However, a further self-selection took place, as not all persons who took a questionnaire filled it in and sent it back (see Section 2.4).

The ambassadors were instructed to conduct the dialogue in an open, friendly and humorous tone. The conversations focused on the disposal behavior of the participants and also included related topics, such as the causes and consequences of littering in general terms and in specific contexts. A questionnaire was developed to analyze the characteristics of the different posters and of the face-to-face communication and to investigate their behavioral effects. The three posters should cover the prototypical characteristics (A) humorous, creative, (B) authoritarian, commanding and (C) environmentally oriented. The corresponding posters were created specifically for the present study. The slogans on these posters were (A) "Because waste has no wings", (B) "Pollution forbidden" and (C) "Protecting the environment". These slogans were placed on otherwise identical posters with the same colors and graphic design and the additional writing "Please, throw waste into the waste bucket". The word "please" was however omitted on the poster with Slogan B to reinforce the authoritarian style. The original posters in German language are depicted in Figure 4 with the English translation of the text provided below. Note that the supposed humorous character of Slogan A stems partly from its reference to a slogan used in an advertising campaign for an energy drink broadly known at the time of the study. 


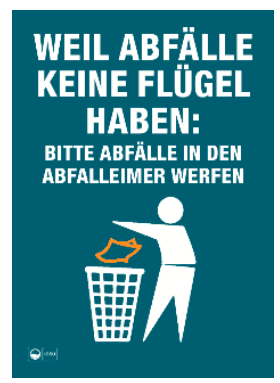

(A)

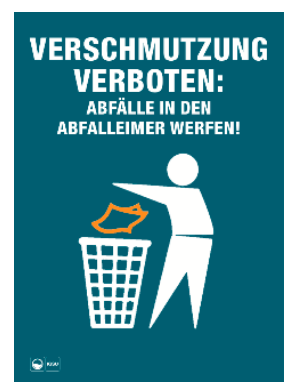

(B)

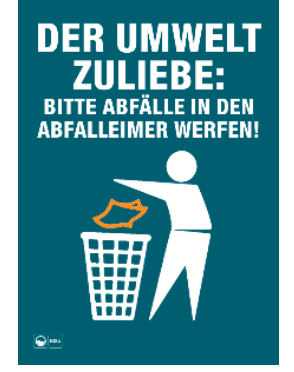

(C)

Figure 4. The three posters used in the study. English translation of the specific texts and main supposed characteristics (in parentheses): (A) "Because waste has no wings" (funny, creative); (B) "pollution forbidden" (authoritarian, commanding); and (C) "protecting the environment" (environmentally oriented).

\subsection{Questionnaire}

The first items of the questionnaire asked for the age and gender of the participants. Then, questions on the three posters were asked. For this purpose, Posters A, B and C were presented separately on three subsequent pages together with the corresponding questions. The sequence of presentation of the three posters in the questionnaires was balanced to prevent systematic order effects. Participants rated for each poster how creative, witty, authoritative, commanding and environmentally oriented they perceived it to be (5-point rating scale from $1=$ not at all to $5=$ very strongly), whether they liked the poster $(1=$ not at all to $5=$ very good $)$ and also whether they think it moves people to dispose of waste properly in the future (effectiveness rating: $1=$ no to $5=$ yes). This was followed by a question on the disposal behavior of the participants. Participants judged their own littering behavior in the past on a 5-point scale from $1=$ never to 5 = very often.

The next part of the questionnaire was only included in the version for the participants who previously took part in a conversation with an anti-littering ambassador. These participants were asked whether they liked the personal conversation with the anti-littering ambassador $(1=$ not at all to 5 = very good), how friendly the ambassador was $(1=$ not at all to $5=$ very much), whether the conversation made them more aware of the problem of the pollution of public space through littering ( $1=$ not at all to $5=$ very much) and whether they think that such a conversation moves people to dispose of waste properly in the future $(1=$ no to $5=$ yes $)$. Analogous to the questions with respect to posters, participants also rated how creative, witty, authoritative, commanding and environmentally oriented they judge the conversation to be $(1=$ not at all to $5=$ very strong $)$.

All questionnaires contained the question about whether the respondents believe that they will display littering behavior in the future $(1=$ never to $5=$ very often). This latter question was formulated analogously to the question on littering behavior in the past, so that a difference measure between past behavior and intentions for the future could be calculated as an indicator of the communication effects.

\subsection{Statistical Analyses and Manipulation Check}

The statistics program SPSS (Version 22) was used for the data analysis. The methods applied for inferential statistics include repeated measurement ANOVAs, contrasts within these ANOVAs, 
independent samples and paired sample $t$-tests, Pearson correlations, chi-square-tests and a binomial test.

A prerequisite for the main hypotheses on the differences between the three posters was that they actually possess the supposed characteristics. The following three manipulation check hypotheses were thus formulated:

Manipulation Check 1: Respondents will consider Poster A as significantly more witty and creative than Posters B and C.

Manipulation Check 2: Poster B will be perceived as significantly more authoritarian and commanding than Posters A and $\mathrm{C}$.

Manipulation Check 3: Poster $\mathrm{C}$ is considered significantly more environmentally oriented than Posters A and B.

To test the manipulation check hypotheses the three posters were compared with regard to each of the five communication dimensions, creative, witty, authoritative, commanding and environmentally oriented, by simple contrasts within five separate one-factorial repeated measurement ANOVAs with three levels representing the ratings for the Posters A, B, C. The analogous approach was taken when comparing the overall judgements and the effectiveness judgements for the posters to investigate the main Hypotheses 1 and 2. The seven repeated measurement ANOVAs, which were thus conducted, assume the sphericity of the repeated measures. This assumption was analyzed for each ANOVA by Mauchly's sphericity test. In case of significant deviations from the assumption, a corresponding epsilon correction of the degrees of freedom using the Huynh-Feldt $\varepsilon$ was accomplished.

The test of Hypothesis 3 (higher effectiveness ratings for the face-to-face communication) only considered the ratings of persons in the experimental condition, since only these persons evaluated both the posters and the face-to-face communication. Hereto, simple contrasts between the effectiveness judgements for the face-to-face communication and each of the three posters were computed within a one-factorial repeated measurement ANOVA with four levels (ratings for the face-to-face communication and the Posters A, B, C).

Hypothesis 4 states that intentions for future behavior would indicate greater positive changes in the experimental condition as compared to the control condition. In the first step of testing this hypothesis, the difference between the self-reported frequency of littering in the past and the expected frequency of littering in the future was computed for all participants. This difference measure served as an indicator for the intention of a positive behavior change and was compared between the two conditions to test Hypothesis 4 by an independent samples $t$-test.

Further information on the statistical methods, which have been used, is provided in the context of their application in the Results Section.

\subsection{Participants}

Altogether, 420 questionnaires were distributed, 210 in each condition. For both conditions, the participants were recruited in the same public places of two different Swiss cities (Bern and Zurich). From these persons, 147 (35\%) sent back their completed questionnaires using the enclosed return envelopes. There were $82(56 \%)$ respondents from the experimental condition and $65(44 \%)$ from the control condition. Thus, the response rate in the condition with face-to-face conversation (39\%) was 
somewhat higher than in the control condition without conversations (31\%). However, according to a chi-square test, this difference was not significant $\left(d f=1, \chi^{2}=3.0, p=0.082\right)$.

Among the participants, $64 \%$ were women and $36 \%$ were men. This is a significant deviation from an equal distribution of gender (binomial test, test value 0.50 , two-sided, $p \leq 0.001$ ). Women are thus over-represented in the present study. The age of the participants ranged from 15 to 86 years with a mean of $M=33.4$ years ( $\mathrm{SD}=17.7)$. There was a tendency of even more women among the respondents in the control condition (70\%) than in the condition with face-to-face communication (59\%), but this difference was not statistically significant (chi-square test, $d f=1, \chi^{2}=2.2, p=0.142$ ). However, the participants who took part in the ambassador conversations were $M=30.8$ years, on average about 6 years younger than the respondents in the control group with $M=36.8$ years (independent sample $t$-test, $p<0.05$ ). The observed age differences could be due to a selection bias in the recruitment (contrary to the sampling instructions) or they may be the results of differential response patterns in the two conditions. In any case, they must be considered when interpreting the results. It has to be kept in mind in this regard that some previous studies indicate that young people tend to display more littering behavior than older persons [38,39].

\section{Results}

\subsection{Manipulation Check and Communication Characteristics}

The repeated measurement ANOVAs comparing the three posters with respect to the ratings for the five communication dimensions, creative, witty, authoritative, commanding and environmentally oriented, were all highly significant (in all five repeated measurement ANOVAs with three levels, $p<0.001$; see Table 1). Simple contrasts within the ANOVAs were calculated to compare the posters with each other (Table 1). Ten out of these altogether 15 mutual comparisons corresponded to the manipulation check hypotheses.

In line with Manipulation Check Hypothesis 1, Poster A "because waste has no wings" was rated significantly more witty and creative than Posters B and C (for all four contrasts, $p<0.001$ ). Consistent with Manipulation Check 2, Poster B "pollution forbidden" was rated significantly more authoritarian and commanding than Posters A and C (for all four contrasts, $p<0.001$ ). Finally, confirming Manipulation Check 3, Poster C "protecting the environment" was considered significantly more environmentally oriented than Posters A and B (for both contrasts, $p<0.001$ ). Thus, all manipulation check hypotheses were clearly confirmed. Accordingly, the three posters can indeed be denoted as "humorous poster" (A), "authoritarian poster" (B) and "environmentally oriented poster" (C). 
Table 1. Comparisons between the three posters and the face-to-face conversation with respect to the ratings for five communication dimensions and overall liking and effectiveness.

\begin{tabular}{|c|c|c|c|c|c|c|c|}
\hline \multirow{2}{*}{$\begin{array}{l}\text { Communication } \\
\text { Dimension a }^{{ }^{2}}\end{array}$} & \multirow{2}{*}{$\begin{array}{l}\text { (A) Because Waste } \\
\text { has no Wings... }\end{array}$} & \multirow{2}{*}{$\begin{array}{l}\text { (B) Pollution } \\
\text { Forbidden }\end{array}$} & \multirow{2}{*}{$\begin{array}{l}\text { (C) Protecting } \\
\text { the Environment }\end{array}$} & \multirow{2}{*}{$\begin{array}{l}\text { Face-to-Face Ambassador } \\
\text { Conversation }\end{array}$} & \multicolumn{3}{|c|}{ Repeated Measurement ANOVAs } \\
\hline & & & & & Number of Cases & $\mathbf{F}$ & Significance $p$ \\
\hline \multirow{2}{*}{ Creative } & $3.9 * *$ & $2.1 * * *$ & $2.9 * * *$ & 3.5 & 77 & 80.31 & $<0.001 * * *$ \\
\hline & $3.8^{\mathrm{x}, \mathrm{y}}$ & $2.1^{\mathrm{x}, \mathrm{z}}$ & $2.9^{\mathrm{y}, \mathrm{z}}$ & --- & 141 & 157.77 & $<0.001 * * *$ \\
\hline \multirow{2}{*}{ Witty } & 3.8 & $1.6 * * *$ & $2.3 * * *$ & 3.8 & 77 & 132.92 & $<0.001 * * *$ \\
\hline & $3.7^{\mathrm{x}, \mathrm{y}}$ & $1.6^{\mathrm{x}, \mathrm{z}}$ & $2.2^{\mathrm{y}, \mathrm{z}}$ & --- & 140 & 212.22 & $<0.001 * * *$ \\
\hline \multirow{2}{*}{ Authoritarian } & 2.0 & $4.1 * * *$ & $2.2 * *$ & 1.8 & 75 & 122.73 & $<0.001 * * *$ \\
\hline & $2.0^{x, y}$ & $4.1^{\mathrm{x}, \mathrm{z}}$ & $2.2^{\mathrm{y}, \mathrm{z}}$ & --- & 138 & 259.12 & $<0.001 * * *$ \\
\hline \multirow{2}{*}{ Commanding } & 1.9 & $4.4 * * *$ & 2.1 & 1.9 & 77 & 234.30 & $<0.001 * * *$ \\
\hline & $1.9^{\mathrm{x}, \mathrm{y}}$ & $4.4^{\mathrm{x}, \mathrm{z}}$ & $2.1^{\mathrm{y}, \mathrm{z}}$ & --- & 141 & 581.96 & $<0.001 * * *$ \\
\hline \multirow{2}{*}{$\begin{array}{l}\text { Environmentally } \\
\text { oriented }\end{array}$} & $3.7 * * *$ & $3.5 * * *$ & 4.5 & 4.4 & 77 & 37.70 & $<0.001 * * *$ \\
\hline & $3.7^{x}$ & $3.6^{\mathrm{y}}$ & $4.4^{x, y}$ & --- & 142 & 61.05 & $<0.001 * * *$ \\
\hline $\begin{array}{l}\text { Confirmed } \\
\text { characteristics }\end{array}$ & Witty, creative & $\begin{array}{l}\text { Authoritarian, } \\
\text { commanding }\end{array}$ & Environmental & & & & \\
\hline \multirow{2}{*}{ Overall ${ }^{\mathrm{b}}$ judgement } & $3.9^{* *}$ & $2.5 * * *$ & $3.7 * * *$ & 4.2 & 81 & 79.12 & $<0.001 * * *$ \\
\hline & $3.7^{\mathrm{x}}$ & $2.4^{\mathrm{x}, \mathrm{y}}$ & $3.6^{y}$ & --- & 146 & 94.85 & $<0.001 * * *$ \\
\hline \multirow{2}{*}{ Effectiveness $^{\mathrm{c}}$} & $3.5 * * *$ & 2.6 & $3.5 * * *$ & 4.0 & 80 & 39.89 & $<0.001 * * *$ \\
\hline & $3.5^{\mathrm{x}}$ & $2.6^{\mathrm{x}, \mathrm{y}}$ & $3.6^{y}$ & --- & 145 & 45.82 & $<0.001 * * *$ \\
\hline
\end{tabular}

Notes: The number of cases varies, because the first line per evaluation criterion encompasses only the cases in the experimental condition, whereas the second line encompasses all participants. In addition, there were occasional missing ratings. ${ }^{\text {a }}$ Scale: $1=$ not at all, $2=$ slightly, $3=$ medium, $4=$ strongly, $5=$ very strongly; ${ }^{\mathrm{b}} 1=$ not at all, $2=$ rather not good, $3=$ average, $4=$ good, $5=$ very good, ${ }^{\mathrm{c}} 1=$ no, $2=$ rather no, $3=$ perhaps, $4=$ rather yes, $5=$ yes. ${ }^{\mathrm{x}, \mathrm{y}, \mathrm{z}}$ Posters with two identical letters (within a row) received significantly different evaluations for the dimension/criterion $(p<0.05)$ according to contrasts within the repeated measurement ANOVA. For the manipulation check hypotheses and the main hypotheses, higher significance levels $(p<0.01$ or $p<0.001)$, which were met, are additionally reported in the text. ** $p<0.01,{ }^{* * *} p<0.001$; upper row per evaluation dimension: repeated measurement ANOVA with 4 levels (evaluation of Posters A, B, C and of the face-to-face communication) and simple contrasts between the face-to-face communication and each poster; lower row per evaluation dimension (all participants): repeated measurement ANOVA with 3 levels (evaluation of Posters A, B, C). 
The mean ratings for the posters on the communication style dimensions are depicted in Table 1 together with the ratings for the face-to-face conversations on these dimensions. With respect to the dimension creativity, the humorous poster was rated highest. The conversation was judged as significantly less creative than the funny poster, but as significantly more creative than the authoritarian and environmentally-oriented posters (Table 1). Regarding wittiness, the humorous poster and the ambassador conversation were both rated significantly higher than the authoritarian and environmentally-oriented posters. Regarding environmental orientation, the face-to-face conversation and the environmentally-oriented poster were rated approximately equally high, whereas the other two posters were judged significantly lower. The ambassador conversation only obtained low ratings for the two dimensions authoritarian and commanding for which the authoritarian poster received by far the highest ratings. Thus, contrary to the poster with the slogan "pollution forbidden", the face-to-face communication, as well as the humorous poster and the environmentally-oriented poster presumably circumvented the elicitation of reactance.

\subsection{Overall Judgement of Posters and Conversations}

An overall judgement for the ambassador talks was elicited with the question "How well did you like the face-to-face communication with the anti-littering ambassador?" on a scale from $1=$ not at all to $5=$ very good. On average, the respondents rated the conversation $M=4.2$, which corresponds to an evaluation slightly above good; $85.1 \%$ of respondents gave a rating of good or very good; not even a single person answered with not at all; and only two people selected rather not $(=2)$. This result shows that the participants of the face-to-face conversations generally esteemed the talks (Figure 5).

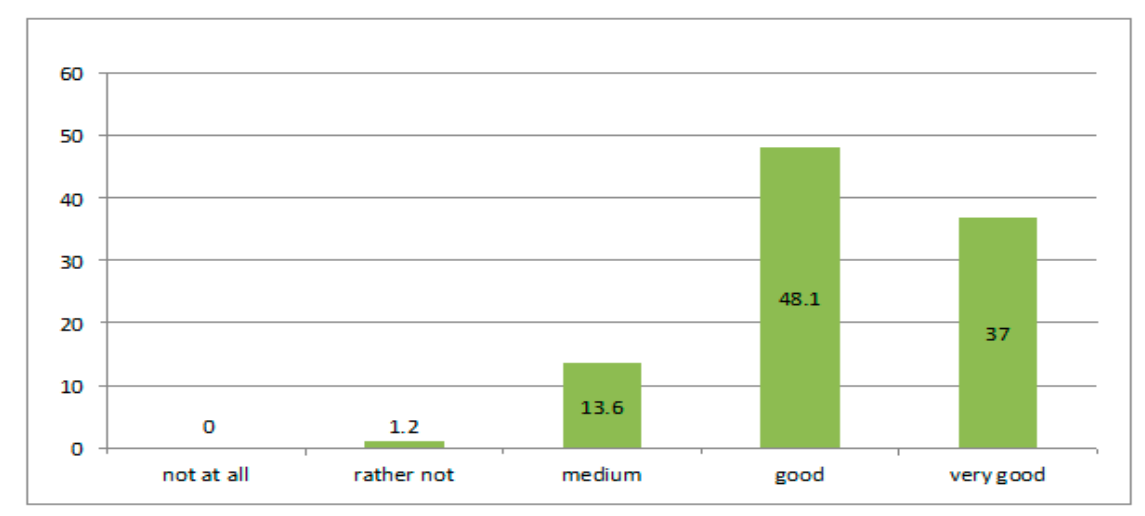

Figure 5. Percentage distribution of responses to the question about whether the participants liked the personal face-to-face conversations $(N=81)$.

The participants were asked to judge on the same scale how well they liked the three posters. A repeated measurement ANOVA on the overall judgements of the posters and the face-to-face communication (four levels) revealed significant differences between the four measurements. Simple contrasts between the face-to-face communication and each of the three posters were computed within the ANOVA (Table 1). It was found that the respondents liked the face-to-face communication significantly better than the humorous poster (contrast, $p<0.01$ ), the environmentally-oriented poster (contrast, $p<0.001$ ) and the authoritarian poster (contrast, $p<0.001$ ). For these comparisons, only the participants in the experimental condition with face-to-face conversations were considered. 
In addition, the ratings for the three posters were mutually compared with each other. Here, the ratings of the whole sample could be considered. A corresponding repeated measurement ANOVA with three measures (overall judgement of Posters A, B, C) was computed and revealed significant differences in the liking of the three posters. Contrasts between the posters showed that the respondents liked both the humorous poster $(M=3.7)$ and the environmentally-oriented poster $(M=3.6)$ significantly better than the authoritarian poster $(M=2.4$; both contrasts, $p<0.001)$. Hypothesis 1 of the present study could thus be confirmed, as the authoritative poster was liked less than the two other posters. There was no significant difference between the witty and the environmentally-oriented poster (Table 1).

\subsection{Effectiveness Ratings for Posters and Conversations}

The question "Do you think that such a face-to-face communication moves people to dispose of waste properly in the future?" elicited judgements of the supposed effectiveness of the ambassador conversations. On a scale from $1=$ no to $5=$ yes, the respondents gave an average rating of $M=4.0$, corresponding to the answer rather yes. Among the participants, $71.6 \%$ answered with yes or rather yes; only two people selected rather no; and no person selected no. Thus, the respondents who participated in such conversations have a fairly high confidence regarding the effectiveness of the ambassador talks. However, there was also a considerable share of participants $(24.7 \%)$, who selected the answer maybe $(=3)$, which indicates that some people are uncertain in this regard (Figure 6).

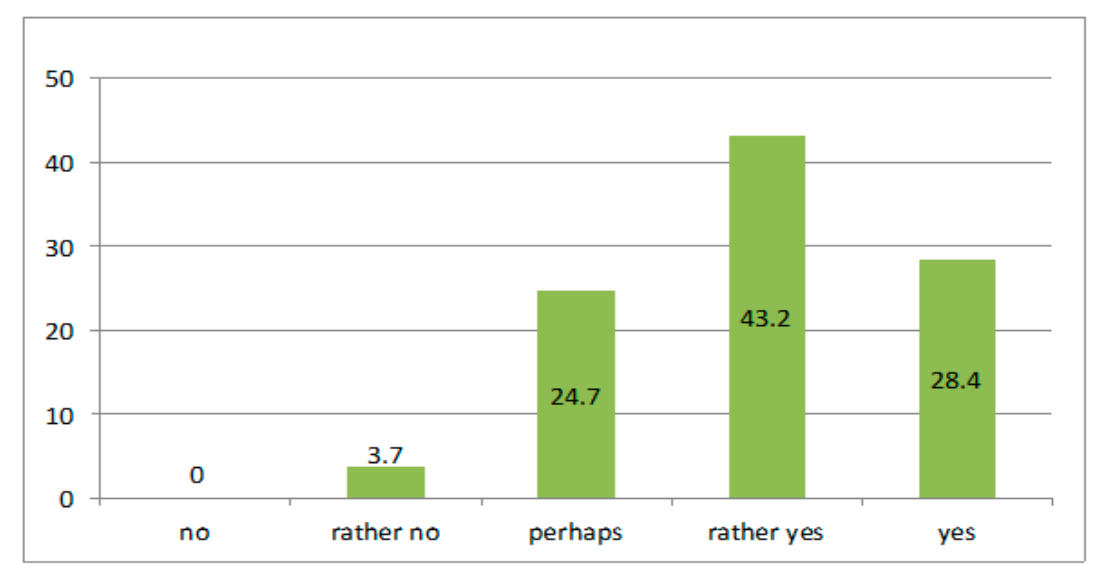

Figure 6. Percentage distribution of responses to the question of whether the anti-littering face-to-face conversations move people to dispose of waste properly in the future $(N=81)$.

Judgements on the effectiveness of the posters were provided on the same response scale as for the conversations. A repeated measurement ANOVA on the effectiveness ratings of the posters and the face-to-face communication (four levels) revealed significant differences between the four measurements. Simple contrasts between the face-to-face communication and each of the three posters were computed within the ANOVA (Table 1). The comparisons of the conversations with the witty, the environmentally-oriented and the authoritarian poster showed that the effectiveness estimates for the face-to-face conversations were clearly higher (for all three contrasts, $p<0.001$ ).

An additional repeated measurement ANOVA with only three measures (effectiveness ratings for Posters A, B, C) was computed and revealed significant differences between the effectiveness 
judgements for the three posters $(p<0.001)$. The effectiveness judgements for the three posters were thus mutually compared with each other by contrasts within the ANOVA. It was found that the humorous poster $(M=3.5)$ and the environmentally-oriented poster $(M=3.6)$ received significantly higher effectiveness ratings than the authoritarian poster $(M=2.6$; both contrasts, $p<0.001)$. The difference between the witty and the environmentally-oriented poster was negligible.

Hypotheses 2 and 3 of the present study were thus confirmed. The witty and the environmentally-oriented posters were judged to be more effective than the authoritative poster, and the face-to-face conversations with the anti-littering ambassadors were considered more effective than each of the three posters.

\subsection{Friendliness and Promotion of Awareness through the Face-to-Face Conversations}

The friendliness of the anti-littering ambassadors was judged by the participants on a scale from $1=$ very low to $5=$ very high with an average rating of $M=4.4$ corresponding to a rating between high (=4) and very high; $93.7 \%$ of respondents gave one of these two ratings. Only one person assessed the friendliness of the ambassadors as rather low and one person as very low.

Participants of the ambassador conversations judged how far these talks enhanced their awareness of the littering problem. On a scale from $1=$ no to $5=$ yes the mean response was at $M=3.4$, which corresponds to a response in the middle between maybe $(=3)$ and rather yes $(=4)$. More than half of the respondents (57.5\%) answered with rather yes or yes, while $25.1 \%$ selected rather no or no.

\subsection{Self-Reported Littering in the Past and Intentions for the Future}

The participants judged the frequency of their own littering in the past on a scale from $1=$ never to 5 = very often. The overall mean of the ratings was $M=2.0$ corresponding to the answer rarely. Almost $30 \%$ of respondents said they have never littered in the past, nearly $43 \%$ selected rarely, almost $25 \%$ occasionally, and only $2.7 \%$ stated that they littered often in the past. Not a single person selected very often. There was a tendency for men to report somewhat more littering $(M=2.2)$ than women $(M=1.9)$, but the difference was not significant (independent sample $t$-test, $p=0.075)$. Consistent with the results of previous studies, littering decreased significantly with the age of the respondents (Pearson correlation: age $\times$ self-reported littering, $r=-0.33, p<0.001$ ).

In the condition with the face-to-face conversation, the average value of self-reported littering in the past was with $M=2.2$, significantly above the mean of $M=1.8$ in the condition without the conversation (independent sample $t$-test, $p<0.01$ ). The overall mean of the ratings of own littering expected in the future was with $M=1.5$, exactly in the middle between rarely and never. There was no significant difference between the expectations for the future in the condition with face-to-face conversations $(M=1.6)$ and without face-to-face conversations $(M=1.5$, independent sample $t$-test, $p=0.252$ ). A comparison of self-reported past behavior with the intentions for future behavior was accomplished separately for the two study conditions. It was found that in both conditions, the level of expected future littering was significantly lower than the level reported for the past (for both paired sample $t$-test, $p<0.001$; see Figure 7). The average absolute value of the difference between the self-reported behavior in the past and the intention for the future was significantly larger in the condition with face-to-face conversation and posters $(\Delta M=-0.6)$ compared to the condition where only 
posters were shown $(\Delta M=-0.3$; independent sample $t$-test, $p<0.01)$. Hypothesis 4 of the present study was thus confirmed. Respondents who took part in face-to-face conversations show a greater difference between the self-reported littering in the past and the intentions for the future as compared to respondents who were only presented with the three posters. Still, the intentions of the participants for the future did not significantly differ between the two conditions. This must be considered when interpreting these findings.

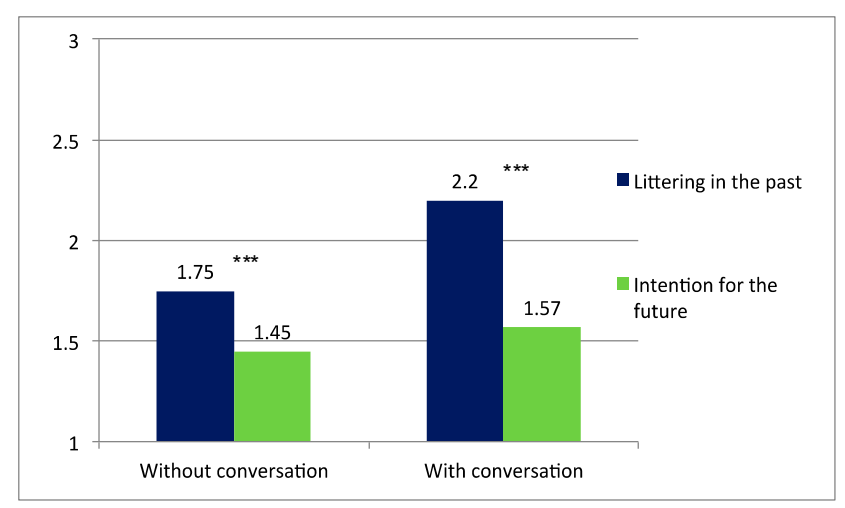

Figure 7. Mean values of self-reported littering in the past and expected future littering in the study conditions "without conversation" $(N=65)$ and "with face-to-face conversation" $(N=82)$ on a five-point scale $(1=$ never, $2=$ rarely, $3=$ occasionally, $4=$ often, $5=$ very often). ${ }^{* *} p<0.001$, significant difference between littering in the past and intention for the future according to paired sample $t$-tests.

\section{Discussion}

The results indicate that face-to-face conversations of anti-littering ambassadors with people in public places are suitable to raise awareness of the littering problem and may bring about positive changes in behavior. Since actual behavior was not observed in this study, drawing definite conclusions in the latter regard would be premature, as additional studies assessing behavior data or objective traces of behavior are required for this.

Still, the participants liked the ambassador conversations and perceived them as an effective way to counteract littering. With respect to these two aspects, the face-to-face conversations were judged significantly better than each of the three posters. Moreover, the intentions for future behavior also improved more in the condition with face-to-face communication and presentation of posters than in the condition where only the anti-littering posters were presented. This suggests that face-to-face conversations can effectively complement posters in environmental campaigns. However, in the condition with the face-to-face conversation, the average value of self-reported littering in the past was higher than in the condition without the conversation, so that the two groups are not fully comparable. An explanation for this difference could be that the ambassadors preferred to recruit people who are inclined to litter for the face-to-face communications. However, it is also possible that the response rate of people who tend to litter was higher in the condition with the face-to-face conversation. For example, it could be that they felt inclined to respond because they perceived the anti-littering ambassadors as friendly. A third possibility is that the conversations initiated a self-critical reflection 
of their own behavior in the past. Thus, it could even be that the face-to-face conversations contributed to the differences between the two conditions in peoples' self-assessment of their own behavior in the past. In the latter case, the conversations may have also promoted awareness of a need to change their own behavior. A laboratory experiment where random assignment is accomplished and differential response rates are eliminated, as (usually) nearly all participants respond to the questions of the experimenters, could clarify whether face-to-face communications can achieve such a critical self-reflection leading to the modification of the self-reports on past littering behavior. This could not be analyzed in this study. However, the current quasi-experimental field study instead possesses high ecological validity, as anti-littering ambassadors were observed in the natural setting of their day-to-day activities. The latter may compensate to some extent for the more thorough analysis of cause and effects relationships that could have been achieved in a psychological laboratory experiment.

Improvements of intentions as compared to past littering behavior could not be measured separately for the three different posters within the current study design, since the three posters were presented to all participants. This is a further restriction of the study, which had to be accepted for pragmatic reasons to obtain a considerably large sample size for judgements with respect to each of the posters. For the same reason, no additional control group without presentation of posters was established. It thus remains unclear whether and to what extent there may also exist a tendency for improved behavioral intentions as compared to past littering behavior in the absence of any intervention. However, posters have been frequently used in campaigns to counteract littering, and in general terms, their effectiveness has already been shown in previous studies [29-32]. In this regard, the present study is consistent with previous findings, which indicated that the use of authoritative, commanding formulations may reduce the effectiveness of posters. In line with these previous findings, the respondents considered the witty and the environmentally-oriented poster as significantly more effective than the authoritarian poster. The high effectiveness ratings and the low ratings that the witty and the environmentally-oriented poster received for "authoritarian" and "commanding" communication style suggest that they effectively circumvented the elicitation of reactance. The same is true for the face-to-face communications, which also received low ratings for both communication style characteristics.

Acknowledging the ratings of overall liking of posters and conversations is important, since in addition to the behavioral effectiveness of a campaign, it is crucial that campaigns and, hence, their elements are well accepted. The acceptance of campaigns is crucial in the long term to ensure the public support required for conducting successive campaigning activities. The witty and the environmentally-oriented poster, as well as face-to-face communications were liked in the present study and, thus, have good potential to be accepted by the public.

The effects that face-to-face conversations can achieve complementarily to posters can be explained on the basis of an integrative model of behavior that takes into account social influence processes, as well as reactance, justifications, habits and other personal and situational determinants of environmental behavior (Figure 3). Counteracting negative habits accordingly involves the problem of altering behaviors, which are performed to a large extent automatically, without too much of an internal deliberation or justification process. The findings of this study show that the ambassador conversations promoted awareness with respect to the problem of the pollution of public space by littering. This 
suggests that these conversations could have also triggered awareness for the need to change their own behavior in the target persons with bad littering habits.

Counteracting justifications is likewise a challenge for environmental communication. Justifications may entail arguments that promote misconduct. When addressing a certain dysfunctional justification for littering in a poster, which is visible to all people, this may even communicate this justification to people who did not even think of it before. On the contrary, the anti-littering ambassadors can flexibly, specifically and selectively address the justifications that are expressed by their counterparts in face-to-face communications. The conversations were rated as environmentally oriented, which suggests that the anti-littering ambassadors promoted the protection of the environment. This may have helped to tackle possible justifications for littering expressed by their counterparts.

Circumventing reactance involves the problem of promoting certain behaviors without commanding people to behave in the aspired way. The participants judged the communication by the anti-littering ambassadors as very friendly, which seems important to avoid the elicitation of reactance. Moreover, friendly communication seems helpful for building a positive relationship between the ambassadors and their counterparts. This may facilitate the development of mutual trust, and various studies have shown that the development of mutual trust is required for solving environmental problems and overcoming socio-environmental dilemmas $[5,6,40]$.

The processes by which face-to-face communication possibly helped to circumvent reactance, tackle justifications and counteract habits as just as have been described have not been investigated in more depth in this study, and therefore, these explanations are speculative to some extent. Examining the content and communication pattern of the anti-littering face-to-face conversations in more detail seems desirable to gain more insights into the social influence process and to derive corresponding recommendations for best practices. To conduct a laboratory experiment where conversations can be recorded and analyzed (or varied) systematically seems important in this regard.

\section{Conclusions and Outlook}

In summary, this study suggests that conducting face-to-face conversations with persons from target groups represents a promising way to counteract littering. Regarding posters, the findings indicate that witty and creative posters focusing on benefits for the environment are more effective and better accepted than authoritarian, commanding ones. However, additional field experiments where actual disposal behavior is observed or behavior traces are analyzed in conditions with different posters and with or without participation in face-to-face conversations are needed to complement the findings of this study through the assessment of objective measures of the effects.

Face-to-face communication and posters may be combined in campaigns against littering to achieve complimentary effects. Including and combining diverse activities in sustainability-oriented campaigns is promising, since different elements of such campaigns have the potential to address different causes or processes that facilitate littering. More research is needed to analyze which measures (e.g., posters, TV spots, face-to-face communication, clean up days, competitions, providing behavioral feedback, waste education in schools, etc.) are suitable to address certain causes of littering and, thus, to achieve changes in behavior. 
Such research should be linked to an integrative environmental behavior model to support the development of anti-littering campaigns that address the diverse determinants of behavior through complimentary elements. An integrative model of behavior has been developed for this purpose with reference to previous research. Among other factors, this model considers reactance, justifications and habit formation, three processes that pose great challenges for sustainability-oriented environmental education and campaigns. Further research is needed on how best to address these challenges for environmental communication and the manifold determinants of environmental behavior.

\section{Author Contributions}

Both authors contributed to the reported research and writing of the paper. They designed and performed the research, analyzed the data and wrote the paper cooperatively. All authors read and approved the final manuscript.

\section{Conflicts of Interest}

The authors declare no conflict of interest.

\section{References}

1. Marion, J.L.; Reid, S.E. Minimizing visitor impacts to protected areas: The efficacy of low impact education programs. J. Sustain. Tour. 2007, 15, 5-26.

2. Balliet, D. Communication and Cooperation in Social Dilemmas: A Meta-Analytic Review. J. Conflict Resolut. 2010, 54, 39-57.

3. Gardner, G.T.; Stern, P.C. Environmental Problems and Human Behavior; Allyn and Bacon: Boston, MA, USA, 1996.

4. Oliver, S.S.; Roggenbuck, J.W.; Watson, A.E. Education to reduce impacts in forest campgrounds. J. For. 1985, 83, 234-236.

5. Ostrom, E. A behavioral approach to the Rational Choice Theory of Collective Action: Presidential address, American Political Science Association, 1997. Am. Polit. Sci. Rev. 1998, 92, $1-22$.

6. Poteete, A.R.; Janssen, M.A.; Ostrom, E. Working Together: Collective Action, the Commons, and Multiple Methods in Practice; Princeton University Press: Princeton, NJ, USA, 2010.

7. Brehm, J.W. A Theory of Psychological Reactance; Academic Press: New York, NY, USA, 1966.

8. Brehm, J.W. Responses to Loss of Freedom. A Theory of Psychological Reactance; General Learning Press: Morristown, NJ, USA, 1972.

9. Agnew, R. The techniques of neutralization and violence. Criminology 1994, 32, 555-580.

10. Sykes, G.M.; Matza, D. Techniques of neutralization: A theory of delinquency. Am. Sociol. Rev. 1957, 22, 664-670.

11. Diekmann, A.; Preisendörfer, P. Persönliches Umweltverhalten. Diskrepanzen zwischen Anspruch und Wirklichkeit. Kolner Z. Soziol. Soz. 1992, 44, 226-251. 
12. Hansmann, R.; Bernasconi, P.; Smieszek, T.; Loukopoulos, P.; Scholz, R.W. Justifications and self-organization as determinants of recycling behavior: The case of used batteries. Resour. Conserv. Recy. 2006, 47, 133-159.

13. Schahn, J.; Bertsch, H.-J. Normdiskrepantes Verhalten im Umweltbereich: EmpirischerTest einer Integration des Normaktivationsmodells von Schwartz und der Neutralisationstheorie von Sykes und Matza. Umweltpsychologie 2003, 7, 128-148.

14. Ajzen, I. The theory of planned behavior. Organ. Behav. Hum. Dec. Process. 1991, 50, 179-211.

15. Armitage, C.J.; Conner, M. Efficacy of the theory of planned behaviour: A meta-analytic review. Brit. J. Soc. Psychol. 2001, 40, 471-499.

16. Corraliza, J.A.; Berenguer, J. Environmental values, beliefs and actions: A situational approach. Environ. Behav. 2000, 32, 832-848.

17. Schultz, P.W.; Oskamp, S. Effort as a moderator of the attitude-behaviour relationship: General environmental concern and recycling. Soc. Psychol. Quart. 1996, 59, 375-383.

18. Stern, P.C.; Dietz, T.; Abel, T.; Guagnano, G.A.; Kalof, L. A Value-Belief Norm Theory of support for social movements: The case of environmental concern. Hum. Ecol. Rev. 1999, 6, 81-97.

19. Lewin, K. Field Theory in Social Sciences; Harper \& Brothers: New York, NY, USA, 1951.

20. Dahlstrand, U.; Biel, A. Pro-environmental habits: Propensity levels in behavioral change. J. Appl. Soc. Psychol. 1997, 27, 588-601.

21. Burnstein, E.; Vinokur, A. Persuasive argumentation and social comparison as determinants of attitude polarization. J. Exp. Soc. Psychol. 1977, 13, 315-332.

22. Lokhorst, A.M.; Werner, C.; Staats, H.; van Dijk, E.; Gale, J.L. Commitment and behavior change. A meta-analysis and critical review of commitment-making strategies in environmental research. Environ. Behav. 2013, 45, 3-34.

23. Latané, B. The psychology of social impact. Am. Psychol. 1981, 36, 343-356.

24. Tanford, S.; Penrod, S. Social influence model: A formal integration of research on majority and minority influence processes. Psychol. Bull. 1984, 95, 189-225.

25. Fehr, G.; Veit, M.; Kamm, A.; Geisseler, L. Littering in der Schweiz-Studie zur Wirksamkeit von Massnahmen unter Berücksichtigung Verhaltensökonomischer Erkenntnisse; Fehradvice \& Partners AG: Zurich, Switzerland, 2014.

26. Stern, P.C. Toward a coherent theory of environmentally significant behaviour. J. Soc. Issues 2000, 56, 407-424.

27. Schwartz, S.H. Normative influences on altruism. In Advances in Experimental Social Psychology; Berkowitz, L., Ed.; Academic Press: New York, NY, USA, 1977; Volume 10, pp. 221-279.

28. Durdan, C.A.; Reeder, G.D.; Hecht, P.R. Litter in a university cafeteria: Demographic data and the use of prompts as an intervention strategy. Environ. Behav. 1985, 17, 387-404.

29. Geller, E.S.; Witmer, J.F.; Orebough, A.L. Instructions as determinants of paper disposal behaviors. Environ. Behav. 1976, 8, 417-439.

30. Hansmann, R.; Scholz, R.W. A two step strategy for reducing littering behavior in a cinema. Environ. Behav. 2003, 35, 752-762.

31. Hansmann, R.; Loukopoulos, P.; Scholz, R.W. Characteristics of effective battery recycling slogans: A Swiss field study. Resour. Conserv. Recy. 2009, 53, 218-230. 
32. Reich, J.W.; Robertson, J.L. Reactance and norm appeal in anti-littering messages. J. Appl. Soc. Psychol. 1979, 9, 91-101.

33. Horsley, A.D. The unintended effects of a posted sign on littering attitudes and stated intentions. J. Environ. Educ. 1988, 19, 10-14.

34. Deci, E.L.; Ryan, R.M. The what and why of goal pursuits: Human needs and the self-determination of behavior. Psychol. Inq. 2000, 11, 227-268.

35. Ryan, R.M.; Deci, E.L. Self-Determination theory and the facilitation of intrinsic motivation, social development, and well-being. Am. Psychol. 2000, 55, 68-78.

36. Hansmann, R. "Sustainability learning": An introduction to the concept and its motivational aspects. Sustainability 2010, 2, 2873-2897.

37. Felser G. Werbe- und Konsumentenpsychologie; Schäffer-Poeschell Verlag \& Spektrum Akademischer Verlag: Stuttgart/Berlin, Germany, 2001.

38. Flury-Kleubler, P. Wer Mull Warum Hinterlässt und Wer Nicht. In Abfall Reihe Kulturhistorische Vorlesungen des Collegium Generale der Universität Bern 2001/2002; Rusterholz, P., Moser, R., Eds.; Lang: Bern, Switzerland, 2004.

39. Krauss, R.M.; Freedman, J.L.; Whitcup, M. Field and Laboratory Studies of Littering. J. Exp. Soc. Psychol. 1978, 14, 109-122.

40. Ostrom, E.; Gardner, R.; Walker, J. Rules, Games, and Common-Pool Resources; The University of Michigan Press: Ann Arbor, MI, USA, 1994.

(C) 2015 by the authors; licensee MDPI, Basel, Switzerland. This article is an open access article distributed under the terms and conditions of the Creative Commons Attribution license (http://creativecommons.org/licenses/by/4.0/). 